\title{
SANTA TERESA Y DON QUIJOTE EN TRES POEMAS GRIEGOS
}

\author{
Miguel CASTILLO DIDIER \\ Universidad de Chile. Chile
}

Resumen: A Nikos Kazantakis, hispanófilo apasionado, le atrajeron profundamente las figuras de Santa Teresa y Don Quijote. A ellos dedicó poemas y no pocas páginas de sus escritos sobre España. En este trabajo, se analizan brevemente esos textos.

Palabras clave: Kazantzakis, Santa Teresa, Don Quijote, canto en tercina.

\section{SANTA TERESA AND DON QUIXOTE IN THREE GREEK POEMS}

Abstract: Nikos Kazantakis, Hispanophile passionate, was deeply attracted by figures of Santa Teresa and Don Quixote. To them he dedicated poems and not few pages of his writings on Spain. In this paper, these texts are briefly discussed.

Key words: Kazantzakis, Santa Teresa, Don Quixote, poem in tercina.

Recibido: 10.07.15 - Aceptado: 26-08-15

Correspondencia: Miguel Castillo Didier.

Email: micastilgriego@gmail.com

Director Centro de Estudios Griegos Bizantinos y Neohelénicos.

Profesor Titular. Universidad de Chile.

Dirección postal: Casilla 435-3 / Santiago / Chile. 
Cinco centurias se cumplen este año 2015 del nacimiento de Santa

Teresa de Jesús y cuatro siglos de la publicación de la segunda parte del Quijote. Oportunidad para recordar estas dos figuras tan señeras en nuestra lengua. Y a propósito de la segunda de ellas, no podemos menos que recordar la reflexión que hacía don Jorge Edwards al hablar aquí de Don Quijote, hace unos meses. Que se recuerda, se estudia se discute, se elogia, a Don Quijote y, en cierta manera, se olvida un poco a Cervantes. Veremos hoy que esto mismo sucede en el texto de autor griego del que hablaremos hoy.

Nikos Kazantzakis, poeta, novelista, dramaturgo, ensayista, pensador griego, muerto en 1957, puede atraer nuestro interés por diversos aspectos de su vasta obra escrita y de su vida "plena de aventuras, plena de conocimientos", para decirlo con un verso de Constantino Kavafis. Hombre de profundas inquietudes espirituales, de atormentadoras contradicciones, admiró a figuras tan disímiles como Buda, Alejandro Magno, Cristo, Mahoma, Dante, Lenin, Nietzsche, El Greco, Don Quijote, Santa Teresa. Sus veintiún cantos en tercinas, escritos durante la década del 30, comenzados precisamente en España en 1932, reflejan en cierto modo las tan variadas aristas de su alma. A través de estos poemas, trataremos de encontrarnos con dos de esos personajes venerados por nuestro autor.

Precisamente, entre los personajes de la hispanidad que admiró y amó especialmente, hay tres a los que cantó en dos poemas en tercinas, en su oceánica Odisea y en una tragedia poética. Con ellos se conoció a través de sus escritos, a través de la lengua castellana en que se expresaron y en la que quedaron plasmados sus anhelos, sus sueños y sus apasionadas luchas.

Ellos son Don Quijote, Santa Teresa y Cristóbal Colón. Sus distintos hablares, reflejos de los distintos azares de sus vidas, conquistaron al poeta griego, desde el magnífico balbuceo del Descubridor, que estudió Menéndez Pidal, hasta el "estilo ermitaño" de Santa Teresa, como lo calificó el mismo sabio, y el inigualable parlar del Caballero de la Triste Figura. Hoy no nos referiremos a Colón, "a quien grandes cosas dictan grandes palabras" y quien por sus escritos tiene un lugar en la lengua castellana. 


\section{La santa de Ávila y su lucha}

Se ha escrito que la santa puede considerarse la cima de la mujer castellana: "Lo es por ser esencialmente una mujer de acción, una reformadora, un carácter voluntarioso e intrépido, movido por una alta espiritualidad. Castilla no sólo es voluntad, sino poesía y creación”. El joven García Lorca, en una carta enviada a sus padres desde Ávila en octubre de 1916, llega a llamarla "la mujer más grande del universo". Juicios parecidos, que quizás podrían parecer hiperbólicos, se han emitido por hombres bien distintos. Así, Gerald Brenan escribe sobre ella: "Se trata de uno de los seres humanos más interesantes que hayan existido jamás. Su carácter era muy complejo, lleno de paradojas y contradicciones, pero compacto en las acción gracias a una fuerte voluntad"2. Y este autor se refiere a las obras de Santa Teresa con estas palabras: "Si se me permite exponer una reacción personal, diré que estos libros cusan una impresión de gran blancura, la blancura de las paredes encaladas [...], la blancura del polvo, la blancura de los cantos de granito de los montes abulenses, la cegadora blancura del sol español"3.

Valbuena Prat también habla del carácter de la Santa: "Teresa es un fuerte temperamento castellano. Lo es por ser especialmente una mujer de acción, una reformadora, un carácter voluntarioso e intrépido, movido por una alta espiritualidad"4.

Sin duda, Santa Teresa es la cima de la mística española y una de las cimas de la lengua castellana. Como escribía Fray Luis de León, la santa "en la alteza de las cosas que trata, excede a muchos ingenios, y en la forma del decir y en la pureza de su estilo y gracia, deleita en extremo. Dudo yo que haya en nuestra lengua escritura que con ella se iguale"s. Su lenguaje, "teñido

1 Carta de 19 de octubre de 1916. Citada por Ian Gibson: Vida, pasión y muerte de Federico García Lorca 1898-1926. Traducción de Ian Gibson, Plaza \& Janés Editores, Barcelon 1988, p. 67.

2 G. Brenan: Historia de la Literatura Española. Traducción Miguel de Amilibia, prólogo G. Torrente Ballester, Ed. Crítico, 2a ed., Barcelona, 1984 p. 171

3 G. Brenan, op. cit., p. 172-173.

4 Valbuena Prat: Historia de la Literatura Española, $3^{\text {a }}$. edición, Editorial Barcelona s. f.

5 Citado en Santa Teresa de Jesús: Poesías y Exclamaciones, Libros Río Nuevo, 
levemente de arcaísmos", posee un claro sabor popular; es en buena medida conversacional.

Teresa y su carácter caracterizado por Brenan, según acabamos de ver, como "muy complejo, lleno de paradojas y contradicciones", no podía sino atraer a Kazantzakis.

Al viajar por España, Kazantzakis reconoce el paisaje rudo, austero, que recorrieron y en el que lucharon el inmortal caballero de la Mancha y la doctora de Ávila. El poeta griego contempla sobrecogido "las altas mesetas de Castilla y Extremadura, vacías de agua, vacías de árboles; rocas por todas partes"6.

"Seca, desértica, obstinada, así es la fragua sita en las alturas en la que se ha forjado el espíritu español"7, escribe en el libro Viajando por España. En el Canto a Santa Teresa, el verso inicial nos ubica en el espacio en que la mujer admirada vivió su lucha por una gran idea:

¡Áspera Castilla, gallarda y desnuda! ${ }^{8}$

Y Don Quijote, en el poema en tercinas, ve en la meseta castellana una patria "desierta e inclemente".

En estas tierras difíciles diversas razas mezclaron sus sangres, hasta que surgió lo que Kazantzakis llama "la sagrada pareja de España": "Finalmente sobrevino el punto álgido, la síntesis profunda, el héroe de todo este país que fundió todos aquellos rostros efímeros y sin conjurar, en un perfil eterno, de modo que España quedara representada ante los grandes comicios del tiempo y del espacio: el santo mártir Don Quijote y, a su diestra, su esposa mística Santa Teresa". Para el escritor griego hay algo común en el impulso a la acción

Barcelona 1990, p. 9.

6 Viajando España, p. 11. Vertido al castellano como España: dos rostros, traducción de J. Maestre, Editorial Lohlé, Buenos Aires 1985.

7 Ibídem, p. 57.

8 La traducción castellana del poema Santa Teresa en N. Kazantzakis: "Cinco cantos en tercinas", Byzantion Nea Hellás. N 16-1997, pp. 168-173.

9 España dos rostros, p. 14. 
heroica, en el llamado a servir hasta el sacrificio a una gran idea, que sintieron, escucharon y obedecieron los dos personajes. Escribe: "Don Quijote y Santa Teresa forman una pareja. Suyo es el mismo e idéntico grito; ambos tienen el mismo propósito: salvar sus almas, o más bien, ofrecerlas con desbordante generosidad, en pro de los más elevados fines" ${ }^{\prime 10}$.

Titánica y heroica fue la lucha de Santa Teresa, su labor reformadora y fundadora. "Esta reforma que emprendió a la edad de cuarenta y siete años dice Lavelle ${ }^{11}$-, debía convertirse para ella en la causa de todos sus tormentos". Y Teresa recuerda que "gran persecución vino sobre nosotras, los dichos, las risas, el decir que era un disparate" ${ }^{12}$, y aunque tiene conciencia de que poseía una "firmeza de alma que no es común en las mujeres"13, le fue duro y difícil superar las contradicciones y persecuciones que relata en los capítulos XXXV y XXXVI de su Vida. Ese combate no podía sino atraer a Kazantzakis.

En la persona y en la lucha de Santa Teresa, Kazantzakis admira la paciencia, la lógica, la alegría, el amor ${ }^{14}$, el tesón, la perseverancia, la resistencia obstinada a penalidades, obstáculos y persecuciones. En ella, en "la más mística de las mujeres españolas", como él la llama, admira el hecho de que jamás perdió "el sagrado sentido común”. Admira junto al misticismo el realismo, ese extraordinario realismo que, en palabras de Lavelle, permite a la santa "percibir las miserables realidades de la condición humana de una manera tan directa, $\tan$ sorprendente y a veces tan cruel, y ese extraordinario idealismo que no era, por así decirlo, sino un realismo espiritual"15. Y sin duda, al poeta de la Odisea, poema en el que viste a los más elevados pensamientos filosóficos con variados elementos sensibles, debía atraer especialmente aquello que según Américo Castro domina en la obra de Santa Teresa: "la transposición de la experiencia sensible al mundo de lo que estrictamente aceptado debiera ser inefable, y que felizmente para nosotros y para el arte, no quiso la santa que

10 Ibidem., p. 61.

11 Louis Lavelle, "Santa Teresa" en Cuatro Santos, trad. de Jorge Zalamea, Editorial Sudamericana, Buenos Aires, 1952, p. 143.

12 Santa Teresa de Jesús: Su vida, $11^{\text {a }}$ ed., col. Austral, Espasa-Calpe, Madrid, 1984, p. 187.

13 Ibid., p. 154.

14 España dos rostros, p. 63.

15 Louis Lavelle, op. cit., p. 140. 
fuera así"16. Teresa no eliminó las injerencias sensibles en la contemplación. Por el contrario, destaca Castro, "las alienta y no las refrena", y agrega: "En ese cándido y misterioso recinto, sede de suaves afectividades, es donde la santa instala lo divino" ${ }^{17}$.

En Viajando por España, Kazantzakis recuerda algunas de las aventuras y penurias de la santa, como las que narra ella misma en los capítulos recién mencionados y también en el primero del libro de su Vida. Y cuenta como preludio al primer éxtasis y pérdida de conciencia de Teresa, el episodio de la monja que, con una pandereta y unas castañuelas comenzó de repente a bailar, llamando a Jesús “¡Venid, venid, ojos queridos! ¡Ven mi dulce Cristo!”18. En torno a este episodio, se entreteje el Canto a la santa. Como en varios de sus poemas en tercinas los dedicados por ejemplo a Dante, a Cristo, a Alejandro Magno, a Don Quijote, en el Canto a Santa Teresa, el tiempo en que transcurre lo que podríamos llamar la "acción” es muy breve; serán algunos minutos.

En la fría y desnuda Castilla, padecen hambre las monjas de un convento:

El pecho les palpita al hambre, al frío

- aves desfallecientes -, pues tres noches,

que ya no tienen pan, fuego, esperanza .(v. 13-15)

Pero la priora, Teresa, que nada ha podido traer esta vez de sus andanzas en busca de ayuda, proclama alegría:
¡Alegraos, hermanas, que en los valles
del cielo pastaremos algún día,
pues no tenemos en la tierra qué comer! (v. 18-20)

Las monjas sufren con imágenes de hogar, de amor, de hijo, de cálida comida. Rudos ángeles, cual barbinegros mozos, empiezan a poblar el nevado patio del monasterio:

16 Américo Castro, "La mística y humana feminidad de Teresa la Santa", Santa Teresa y otros ensayos, Editorial Historia Nueva, Santander, 1929, p. 38.

17 Ibidem., p. 39.

18 España dos rostros, p. 62. 
De pie sobre la nieve, ve la priora sonriendo el fantástico cortejo:

- De Jericó, mis rosas, ya vendrá, nupcial tormenta, se abrirá la carne, y todas, hartas, os aliviaréis en la copiosa inundación de nuestro Dios". (v. 46-51)

Y cuando una de las religiosas salta y desatándose el cabello proclama su oculto deseo "Ven, mi Jesús, dulce adorado mozo", la priora es arrebatada por misteriosa mano:

Llameante rompe saeta encarnada

el seno de la priora y una mano

del cráneo oculta cógela con fuerza.

Cual águila en el aire convulsiónase.

Se cogió de la puerta, resistiendo,

pero un ala azulosa la golpea

y hasta el centro del patio precipítala.

Una llama brotó a su lado izquierdo:

crece, coge a la tierra; en fiera red

de espeso fuego el monasterio envuélvese,

se sume entero en tempestad helada. ( v. 58-69)

Largas son las palabras de la priora. Ocupan sesentitrés de los ciento cincuenticuatro versos del poema. A través de ellos, Kazantzakis, con su lenguaje, expresa la comunicación mística de la santa con Dios:

¡Ven, mi Jesús, dulce adorado mozo!

Arde, florece el pobre monasterio:

¡ceniza vuélvase, y veamos al Amado!

La mente se embriagó, dan flor los yermos senos;

¡caminar ya no puedo y me suspendo

cual abeja de espaldas en la rama

florida del Señor y allí me cimbro!

Soy, Dios mío, mujer: tan dulcemente

sólo contigo puedo yo aunarme;

siento el dolor de nuestra tierra hembra

al diluvio del cielo, y el celeste 
de la noche temor bajo los rayos. (v.79, 85-95)

Los versos siguientes son un desarrollo del celebérrimo verso "que muero porque no muero" "19. La unión mística con Dios en la tierra son sólo esponsales y duran demasiado. Sólo la muerte trae la unión verdadera, tan deseada:

Eh Caronte, amoroso niño mío, el alma mía toma de la mano y por tu oculto canal subterráneo guíala hasta el Amado, que ¡ay de mí!, esperanza más grande yo no tengo.

¡Ah, morir es mí la sola salvación! (v. 102-6, III)

No falta una palabra para la vida, mientras se pide la muerte, que es la verdadera boda después de los esponsales terrenos:

Buena es la gracia de la tierra y mar y la fragancia de la selva húmeda, cuando el cuclillo canta en primavera... mas mucho se alargó la vida, oh Dios, y mucho duran ya tus esponsales. ¡De tu místico vendaval con la pasión el cuerpo - ese tabique - se destroce, novia desnuda salga el alma y tiemblen de corola a raíz las azucenas! (v. 116-124)

Derretirse en el fuego divino, fusión mística con el Amado; que venga Dios cual catarata y que beba el alma y se sacie. Y las exaltadas palabras concluirán con el ruego a Jesús, el adorado mozo:

Cirios somos en fila al aire ardiente:

¡a derretirnos, que otra dicha no hay!

Vengan ya los heraldos de las bodas;

sofocado de amor, avanza, oh cuerpo.

¡Ven, mi Jesús, dulce adorado mozo,

19 Santa Teresa, Poesías y Exclamaciones, p. 14-17. 
ven para siempre ya, ven para siempre! (v. 137-143)

Cesaron las palabras de la priora. El Paraíso entrevisto se ha esfumado; pero el hambre se calmó y la virginidad ha gozado el abrazo divino. Todo fue un relámpago y pasó,

\section{¡pues breve instante es la inmortalidad!}

Don Quijote es acaso el personaje que más admiró Kazantzakis en España, el país al que seguramente también admiró más, después de Grecia. Uno de los cuatro guiones que escribió a comienzos de 1932 es "Don Quijote". Imaginó entonces una película, que sólo quedó en eso: en la imaginación. Dos años después, en 1934, dedicó al caballero inmortal un canto en tercinas, en 162 endecasílabos. Con el nombre de Capitán-Uno, Don Quijote aparece en la Odisea como un luchador heroico al que tanto Ulises como el poeta admiran. $Y$ en el libro Viajando por España $a^{20}$, en su forma definitiva, el Caballero de la Triste Figura es, entre los personajes españoles allí recordados, el que recibe más epítetos admirativos; y su imagen se asocia a las de otros que causaron profunda impresión en Kazantzakis, como Santa Teresa y Unamuno. Y como recordábamos al comienzo, pese a haber escrito en tres obras acerca de Don Quijote, no encontramos en Kazantzakis expresiones de admiración por Cervantes.

Don Quijote integra la galería de personajes venerados por el escritor cretense, de esos "guías" o "conductores" de su espíritu, a quienes dedica cantos en tercinas y varias de sus tragedias: Buda, Moisés, Alejandro Magno, Cristo, Mahoma, Dante, Santa Teresa, Cristóbal Colón, el Greco, Nietzsche, Lenín. En ellos ve principalmente un rasgo: la capacidad para empaparse por una "gran idea" y para sacrificarse por ella, arder en su llama. Muchas veces el camino de esa gran idea ha llevado al martirio, al sacrificio. De ahí que la palabra "mártir" la hallemos más de una vez en las referencias a varias de esas figuras admiradas. Gran mártir es Colón ${ }^{21}$; santo mártir es Don Quijote 22 ; mártir es Cristo; mártir, Constantino Paleólogo; gran mártir, Nietzsche.

20 Ha sido traducido al castellano por Joaquín Maestre y publicado con el título de España dos rostros, Carlos Lohlé, Buenos Aires, 1985.

21 España dos rostros, p. 36.

22 Ibidem., p., 14. 
Mucho dice la dedicatoria que dejó escrita Kazantzakis al comienzo de su colección de cantos en tercinas, que, como sabemos, no llegó a publicar en vida: "Estos versos están dedicados a las dos más elevadas palabras que han creado hasta ahora el orgullo y la altivez del hombre: desperado, nada"23. En esa dedicatoria, como vemos, Kazantzakis usa la forma arcaica "desperado" y no "desesperado". Y en Viajando por España explica en cierto modo el porqué escribió esos términos en nuestra lengua castellana: "Nada, nada. El grito más profundo y característico del espíritu español: su conciencia de la nada, de que la vida es un sueño"24.

Sobre esta idea de la nada, escribe desde Madrid en 1932 a su amigo Renaud de Jouvenel: "Mirar la nada a la cara: he aquí lo que me gusta y que lo encuentro aquí en la tierra, el aire y los molinos de viento de nuestro Señor Don Quijote".

Y la lucha sin esperanzas, "desesperada", que constituye el mandamiento de la Ascética, su opúsculo filosófico-poético, la ve Kazantzakis simbolizada en la empresa de Don Quijote. Cuando afirma que "la vida es una lucha mortal del amor y la muerte", iguala esta lucha a "una terrible aventura de Don Quijote, sin esperanza y valiente"25. Y repite esta idea: "Somos sollozos hechos de carne y nadie nos oye. Y sin embargo, lo cierto es que gritaríamos y nos rebelaríamos, como Don Quijote, al negar la muerte, incluso en el momento mismo de nuestro fin" 26 .

Larga es la lista de las formas en que nombra Kazantzakis a su admirado personaje: santo mártir, gran príncipe, caballero del ideal, ardiente héroe de la Mancha, eternamente errante caballero del ideal, gran espíritu, soñador que no quería salir de su sueño, temerario e ingenuo amante de la idea y de la cruel Dulcinea, caudillo de las almas de los mortales como Hamlet, Fausto y Ulises. Algunas de estas expresiones que leemos en Viajando por España las hallamos en el canto en tercinas, y encontramos otras: grande asceta, anciano conductor, ardiente señor del arenal, valiente lancero, grande mártir, el sin

23 N. Kazantzakis, Tersines, Ediciones Heleni Kazantzaki, con nota de E. Kásdagli, Atenas, 1960, p.

24 España dos rostros, p. 24.

25 Ibidem, p. 150.

26 Ibidem., p. 115. 
esperanza, la mayor esperanza de la tierra viuda, el tesoro más puro y preciado de Dios, postrer trinchera inexpugnable de Dios, gran atleta, anciano jefe, gran combatiente, Capitán-Uno. Este último nombre es el que predomina en la rapsodia vigésima de la Odisea, donde Ulises lo nombra también como "noble de la imaginación", "ala roja de la tierra" y simplemente "capitán”, mientras que Don Quijote se califica a sí mismo de

"pájaro inmortal, que cuando me vuelvo pavesas, brinco alegremente desde mis cenizas, y las llamas

/ que me devoraron

se truecan en alas largas-como-remos y ascienden

/ hacia Dios"27.

En su caminar por España, Kazantzakis sigue con emoción las huellas de Don Quijote. Citemos sólo dos pasajes de los varios en que recuerda al gran combatiente. "Contemplé las piedras, respiré el aire de Castilla (...). Me di cuenta de que habíamos llegado al devastado y demencial territorio del gran príncipe Don Quijote. Él era aquí, en esta estepa, el gran señor. Fue aquí donde el caballero del ideal emprendió la marcha para liberar a los esclavos, reparar los agravios de aquellos que habían sido tratados injustamente, proteger a los huérfanos y a las viudas, deshacer entuertos y luchar contra las bajas pasiones del mundo, la envidia, la injusticia, el temor, la deshonestidad, la pereza, la arrogancia" 28 .

Don Quijote vive intensamente y por eso sigue "el método más seguro y fructífero" que "ha sido siempre el camino de la fe y del ascetismo". $\mathrm{Su}$ propósito en la tierra ha sido salvar su alma o más bien "ofrecerla con desbordante generosidad en pro de los más elevados fines". La santa locura de este santo mártir, "el grito de Don Quijote contra la razón (que, en realidad, es el más profundo alegato en favor de ésta) dejó oír su estruendo entre los seres humanos prácticos y razonables" ${ }^{\prime 29}$. Comparte Don Quijote este don de la santa locura con una reina Isabel la Católica, con un Cristóbal Colón, a quien Kazantzakis recuerda precisamente con el apodo de Wasserman, “el Don

27 N. Kazantzakis, Odisea, Introducción, traducción, síntesis y glosario M. Castillo Didier, Tajamar Ediciones, Santiago 2013, Rapsodia XX, v. 213-215.

28 España dos rostros, pp. 38-39.

29 Ibidem, p. 15. 
Quijote de los mares"30. Arreglar el mundo, corregir las injusticias, es la misión que impone esa santa locura: "El mundo salido de las manos de Dios estaba plagado de defectos e injusticias y el caballero estaba obligado a arreglarlo. Porque la obra de Don Quijote comienza allí donde Dios la abandona"31. La empresa de ese gran espíritu es hermosa, es sublime, y cuando después de la derrota debe volver humillado, Kazantzakis siente honda amargura, pues -dice - "somos profundamente conscientes de cuán abominable es esta vida, que sólo recompensa los proyectos fríos y calculadores, despreciando las empresas nobles y generosas" 32 .

Este juicio nos recuerda el del Libertador Simón Bolívar cuando, ante las excusas por la pobreza de su biblioteca que le dio Joaquín de Mier, el español en cuya casa halló paradojalmente refugio final - caído, proscrito y agonizante -, respondió con estas palabras: “¿Cómo puede ser pobre esta biblioteca, cuando tiene en ella la historia de la humanidad: Gil Blas, el hombre tal cual es; y Don Quijote, el hombre como debiera ser" ${ }^{33}$.

El hombre como debiera ser, siempre ascendiendo, siempre luchando sin esperanza. En el canto en tercinas, al grito de libertad del alma humana "se alza el gran combatiente" y, al consolar al alma, define su misión, complementaria de la de Dios:

Lo que no terminado dejó Dios

yo lo he de terminar, yo el combatiente ${ }^{34}$. (v. 16-18)

Ante el mundo hostil, desértico, en que debe combatir; ante la tentación de la dulzura y la quietud del hogar, el gran asceta reafirma su voluntad de combate por la libertad, desechando las advertencias de su cuerpo temeroso y de su débil caballo. Prefiere escuchar, como en la Odisea, a su corazón, el cual, en

30 Ibidem., p. 37.

31 Ibidem., p. 39.

32 Ibidem., loc. cit.

33 Mario Briceño Perozo: La espada de Cervantes, p. 211.

34 La traducción castellana del poema Don Quijote en N. Kazantzakis, Cinco cantos en tercinas, trad. e introducción Miguel Castillo Didier, en Byzantion Nea Hellás, $\mathrm{N}^{\mathrm{o}}$ 16. Homenaje a Kazantzakis, Centro de Estudios Bizantinos y Neohelénicos, Universidad de Chile, Santiago, 1997, pp. 156-160. 
largo parlamento, desde el v. 50 al 129, le hace entrever las penurias y pruebas que le aguardan, esa dura lucha que es como "comenzar una segunda creación". Prevé la senda ardua en la que tendrá por compañero sólo al hambriento Caronte, ese león. Aquí Kazantzakis personifica la muerte en Caronte, el negro caballero de la mitología popular neogriega, que sale en su negro corcel a llevarse a los humanos. Pero tan voraz es que el poeta lo compara con un león.

Las consignas del luchador coinciden con los mandamientos de la Ascética:

Adelante, sin esperanza alguna. (v.61)

¿Qué es en la creación lo más difícil?

Nuestro pecho eso busca sin temblar. (95-96)

Atrás quedan la vida pequeña y el mezquino sentido con sus estrechos límites:
Altas montañas, oh alegría, nuestra frente golpeada es por los puros vendavales:
ya hemos roto de la prudencia el freno... (v. 91-2, 4)

Don Quijote elige el camino duro del ascenso, a través de la lucha, para terminar lo que inacabado dejó Dios y por corregir lo malo que ha añadido el hombre a la creación: la injusticia.

¡Mi Dios, nunca vi tanto veneno!, ni patria tan desierta e inclemente:

Ah, la senda de Dios creo he tomado. (v.25, 27-8)

Como a Cristo en La última tentación, la tentación de una casita hermosa, una tierna mujer y un hijo amoroso, no vence a Don Quijote. No atiende al clamor de su débil caballo y de su escuálido cuerpo, sino a la voz de su corazón, que anuncia un camino sin esperanzas, duro y sangriento, con la dulce Dulcinea inexistente como guía y el hambriento Caronte por compañero:

Este es el reino de la idea;

serpientes venenosas son sus bienes,

y sólo hay una rosada flor, 
el secreto perfume de la amada, de nuestra Dulcinea inexistente. Y seguiremos de por vida jadeantes por nuestra senda las amadas huellas; pero sólo como sedientos perros sobre las piedras lameremos nuestra sangre y un solo fiel tendremos compañero: al hambriento Caronte, ese león. (v. 50-60)

Al final del poema, divisamos la figura ascética en silencioso ascenso por la pendiente de su propia alma:

Estrellada la vasta medianoche

llorando se deshoja sobre él; mas en silencio él espolea su caballo, y lentamente y sin aliento asciende la pendiente sin esperanza de su alma (v.158-162)

En la Odisea, en esa poliédrica narración de la nueva y postrera peregrinación de Ulises en búsqueda de sentido para la existencia humana, o en busca de Dios, como se ha dicho, el Capitán-Uno, Don Quijote, es uno de los últimos personajes con quienes contrasta aquél su visión del mundo. Desde su llegada al Africa, Odiseo ha ido hallando a diversos hombres, varios de ellos representativos de tipos humanos que han sido recogidos en la literatura mundial, como Hamlet, Fausto y otros. En la rapsodia vigésima, conocerá al Capitán-Uno. En la rapsodia siguiente, hallará al último, al joven pescador negro que representa a Cristo.

Cabalgando en un viejo camello, el Capitán-Uno ha salido al mundo a combatir las injusticias y ha caído en poder de una tribu de antropófagos. Está a punto de ser quemado, cuando Ulises llega al lugar y logra salvarlo. El contrapunto entre los dos personajes deja de manifiesto la profunda admiración de Odiseo por el viejo luchador a quien la gente tiene por loco. El Capitán-Uno "alto, delgado y desgarbado, ancha su cabeza cual una bandeja; sus viejas heridas pintadas, su cabello enmarañado", oye el clamor de viudas, huérfanos, cautivos y jornaleros maltratados. Ningún argumento lo detiene en su propósito; y así responde a su madre que trata de disuadirlo: 
¡Madre, ama el corazón y no pregunta, y llama!

Madre, al hombre compadezco y no quiero la injusticia;

iparto a llevar libertad y pan y amor a los humanos!

(XX, v.89-91)

A sus primeros reveses le sucede la caída en manos de antropófagos que van a quemarlo y devorarlo. El anciano invoca a la libertad, seguro de que otros vendrán tras él. Es el momento en que llega el asceta Odiseo:

¡Enhorabuena nos hemos encontrado con este nuevo

/ compañero

Brinca ya la llama y los asadores están listos, y él permanece

/ erguido:

¡muere negando a la muerte e invoca a la libertad!

¡Eh anciano nudoso, tu locura es pareja de la mía!

/ (XX, v. 174-7)

También el Capitán-Uno se siente identificado con Ulises y quisiera compartir con él la salvación del mundo:

¡Enhorabuena viniste hacia nosotros, mi hermano

/ igual a mí!

Vamos a partir nosotros dos a fin de salvar al mundo;

yo caeré delante con mi espada y te abriré camino;

romperé yo las cadenas de la esclavitud, destruiré

\section{/ las fortalezas (XX, v. 191-4)}

Más de una vez, Odiseo reitera su admiración al combatiente. Éste ha pronunciado su invitación a la lucha, estando atado para ser muerto. Por eso, el asceta le dice:

¡Salud, hermano, que niegas lo que estás viendo y cantas / en la hoguera! (XX, v. 201)

Y cuando finalmente Ulises logra liberarlo, explica así su acción a los antropófagos: 
¡Eh cabezas motudas, escuchadme una palabra!

No he dejado roca por volver, vagué por continentes

/ y por mares,

para poder juntarme con este noble de la fantasía;

y las alas que Dios no me dio, éste me las ha de dar.

Una nodriza nos amamantó; una leche nos alimentó.

/ (XX, v. 257 y261)

La idea de querer perfeccionar el mundo, no terminado por Dios, que se expresa en el canto en tercinas y en el libro sobre España, aparece aquí, cuando, ante la observación de Ulises acerca de las escasas fuerzas y pocos medios del Capitán-Uno, éste responde:

Yo no estoy desarmado; la justicia es mi broquel.

Imperfecto salió el mundo de las manos del Señor.

Y yo debo partir, solo, para perfeccionarlo.

En tanto la injusticia, el temor, la esclavitud,

/ al mundo tiranicen,

¡he jurado la espada nunca dejar libre, hermano mío!

/ (XX, v. 290-4)

La santa locura que pondera Cristóbal Colón ante la Reina Isabel en la tragedia homónima, es elogiada con palabras conmovidas por UlisesKazantzakis, al despedirse del Capitán-Uno, que se ha lanzado a tratar de liberar a los esclavos que llevan los antropófagos:

Dentro de tu sueño te has atrincherado y ya no quieres salir, ¡y ya no aceptas, águila, caminar por la tierra!

$$
\text { / (XX, v. 303-4) }
$$

Sabes bien que has de quemarte y de perderte en la llama, pero haces de la pérdida un asalto y un ala de la pobreza; bendito tu tiempo, hermano, y nunca vuelva tu entendimiento

/ a sus cabales;

¡eres el ala roja de la tierra y otra ala no existe!

/ (XX, v. 311-14) 
Santa Teresa y Don Quijote. Dos personajes con que la España y la lengua española están y estarán presentes en los comicios del tiempo, como dice Kazantzakis. En ellos, la lengua de Castilla, que es nuestra lengua, fue el vehículo de sus sueños, de sus ideales, de sus anhelos, de sus combates. A través de esa lengua los descubrió, los admiró y los amó el poeta griego. Y los cantó en la lengua griega. 


\section{BIBLIOGRAFÍA}

BRENAN, G. (1984) Historia de la Literatura Española. Traducción Miguel de Amilibia, prólogo G. Torrente Ballester, Barcelona: Ediciones Crítico. BRICEÑO PEROZO, M. (1987) La espada de Cervantes. Buenos Aires: Imprenta López.

CASTRO, A. (1929) "La mística y humana feminidad de Teresa la Santa”. En Santa Teresa y otros ensayos. Santander: Editorial Historia Nueva

GIBSON, I (1988) Vida, pasión y muerte de Federico García Lorca 1898-1926. Traducción de Ian Gibson, $2^{\mathrm{a}}$ ed. Barcelona: Plaza \& Janés Editores.

KAZANTZAKIS, N. (1997) “Cinco cantos en tercinas”. Traducción M. Castillo Didier. En Byzantion Nea Hellás. ํㅜ 16.

-, (1985) España: dos rostros. Traducción de J. Maestre. Buenos Aires: Editorial Lohlé.

-, (2013) Odisea. Introducción, traducción, síntesis y glosario M. Castillo Didier. Santiago: Tajamar Ediciones.

-, (1960) Tersines. Nota de E. Kásdagli. Atenas: Ediciones Heleni Kazantzaki.

LAVELLE, L. (1952) “Santa Teresa”. En Cuatro Santos. Trad. Jorge Zalamea. Buenos Aires: Editorial Sudamericana.

SANTA TERESA DE JESÚS (1990) Poesías y Exclamaciones. Barcelona: Libros Río Nuevo.

SANTA TERESA DE JESÚS (1984) Su vida. $11^{\mathrm{a}}$ ed. Madrid: Editorial EspasaCalpe.

VALBUENA PRAT, A. (s.f.) Historia de la Literatura Española, $3^{\mathrm{a}}$. edición, Barcelona: Editorial Gustavo Gili. 